\title{
PRECONCEITO LINGUÍSTICO COM \\ MENORES EM REGIME DE PRIVAÇÃO DE LIBERDADE
}

\begin{abstract}
Rodrigo Mazer Etto Mestre em Estudos da Linguagem pela Universidade Estadual de Ponta Grossa (UEPG) etto.rodrigo@gmail.com

Valeska Gracioso Carlos
\end{abstract} Doutora em Estudos da Linguagem pela Universidade Estadual de Londrina (UEL) Professora Adjunta da Universidade Estadual de Ponta Grossa (UEPG)

vgracioso@uol.com.br

\section{RESUMO}

O presente artigo é um recorte de uma pesquisa cujo objetivo foi o de identificar e analisar a ocorrência de situações de preconceito linguístico vivenciadas, em decorrência do uso da gíria, por adolescentes em cumprimento de medidas socioeducativas de privação de liberdade. A etapa de geração e coleta de dados foi realizada por meio da aplicação de entrevistas narrativas, de acordo com a teoria de Tarallo (2003). As análises das narrativas se fundamentaram nos referenciais teóricos de Bagno (2002, 2004), Calvet (2002) e Preti (1977, 1984), e permitiram constatar que os quatro adolescentes entrevistados vivenciaram situações de discriminação linguística devido ao uso da gíria.

Palavras-chave: preconceito linguístico, gíria, adolescentes infratores.

\begin{abstract}
The present article is a research clipping which objective was to identify and analyze the occurrence of linguistic discrimination situations experienced, due to the use of slangs, by adolescents in deprivation of liberty - compliance with socio-educational measures. The stage of data generation and collection was performed through the application of narrative interviews, according to Tarallo's theory (2003). The narratives' analysis were based on the theoretical references of Bagno (2002, 2004), Calvet (2002) and Preti (1977, 1984), and allowed to verify that the four adolescents interviewed experienced situations of linguistic discrimination due to the use of slangs.
\end{abstract}

Keywords: linguistic prejudice, slang, adolescents in deprivation of liberty. 


\section{Introdução}

A língua permite a interação entre o seu usuário e a sociedade, funcionando como um elemento cultural revelador da visão de mundo do falante e do grupo social ao qual pertence, já que "um povo se individualiza, se afirma e é identificado em função de sua língua" (SCHERRE, 2008, p. 10).

Paralelamente, é relevante considerar que as línguas, ao contrário de serem fixas ou imutáveis, estão em constante processo de mudança, em decorrência da influência de fatores internos e externos ao sistema linguístico, o que denota a natureza heterogênea da língua. Tal caráter heterogêneo possibilita a coexistência, na sociedade, de modos diferentes de se dizer a mesma coisa, pois cada grupo social vive uma realidade específica e a reflete através da linguagem praticada por seus integrantes. Logo, realidades diferentes vividas por grupos sociais diferentes originarão formas diversas de manifestações linguísticas.

Dentro desse conceito de mudanças no uso da língua, a variedade linguística conhecida como gíria (PRETI, 1984) - utilizada por adolescentes em cumprimento de medidas socioeducativas de privação de liberdade - apresenta um paradoxo: de um lado, ela facilita a comunicação entre os integrantes desse grupo social e cria uma identidade linguística que possibilita diferenciar tal grupo dos demais grupos presentes na sociedade; de outro lado, ela expõe seus usuários a situações discriminatórias frente a indivíduos ou instituições que defendem o uso da variedade linguística considerada padrão, vista como a forma correta de se usar a língua.

A principal característica da gíria está relacionada ao plano semântico-lexical, em que são atribuídos a alguns termos e expressões significados diferentes daqueles 
presentes na linguagem comum, ou seja, há a alteração do sentido original de algumas palavras, dado que através do seu uso "a realidade se transforma em signos, pela associação de significantes sonoros a significados arbitrários" (PRETI, 1977, p. 02).

Tendo em vista as transformações possíveis de ocorrer na língua, sua identificação a determinados grupos sociais e sua relação com uma maior ou menor aceitação social, o presente artigo objetiva analisar algumas ocorrências de preconceito linguístico experienciadas por quatro adolescentes de um Centro Socioeducativo.

Assim, este trabalho se divide em quatro partes. A primeira abordará os fatores que motivaram este estudo. A segunda parte esclarecerá sobre a metodologia utilizada de geração e coleta de dados. A terceira apresentará os itens lexicais com sentido figurado que foram identificados nas respostas dos participantes. E a quarta seção trará a análise das narrativas.

\section{A infração na adolescência e a linguagem}

Segundo Erikson (1994), a adolescência é uma fase do desenvolvimento humano na qual o indivíduo encontra-se vulnerável às influências do meio, por sofrer significativas transformações físicas, psíquicas e emocionais. Salles (2005) complementa que nessa etapa de vida muitos valores são contestados, repensados e modificados de acordo com vários fatores, dentre os quais o ambiente em que o adolescente vive e o grupo social ao qual pertence ou deseja pertencer.

Um fator importante que motivou o presente estudo relaciona-se com o crescente número de adolescentes cumprindo medidas privativas de liberdade no Brasil. Os dados de 2015 do Cadastro Nacional de Adolescentes em Conflito com a Lei (BRASIL, 2016) 
indicaram o dobro de adolescentes cumprindo medidas socioeducativas no Brasil, em comparação aos 96 mil registrados em 2013. Dos mais de 192 mil adolescentes cumprindo medidas socioeducativas, 58.079 adolescentes cumpriam medidas privativas ou restritivas de liberdade.

De acordo com o mais recente Levantamento Anual do Sistema Nacional de Atendimento Socioeducativo (BRASIL, 2018), referente a 2016, dentro de um total de 201.032.714 brasileiros, a população total adolescente correspondia a 26.154.356 indivíduos, sendo que destes, 23.868 adolescentes se encontravam cumprindo medidas privativas de liberdade em Centros Socioeducativos.

Em seu trabalho intitulado 'A vida em rebelião: jovens em conflito com a lei', Vicentin (2005, p. 33) destaca que a infração na adolescência, além de sujeitar o indivíduo a "profundas transformações biológicas, psicológicas e sociais - características dessa etapa da vida -, contribui para o surgimento de conflitos internos, exigindo deste a ressignificação de sua subjetividade e da sua relação com o mundo". Tendo em vista que tal relação é conflitiva, essa autora esclarece que, juntamente com as mudanças citadas anteriormente, o ambiente e o contexto sociocultural nos quais se localiza o adolescente propiciam mudanças no seu comportamento linguístico.

Nessa mesma linha, Preti (1977, p. 8) destaca o "meio físico e social como um importante fator extralinguístico na criação de um tipo especial de expressão", pois tal fator engloba as condições de vida exigidas nesse contexto ambiental e as necessidades comunicativas das pessoas que nele convivem.

As características de um Centro Socioeducativo, nas quais se destacam o convívio forçado entre adolescentes com históricos de vida ligados à violência, a necessidade de adequação às regras impostas pela população geral de internos, a restrição de circulação, 
a segregação social e, principalmente, a sensação constante de estar sendo vigiado, favorecem a criação e adoção de uma variedade linguística marcada pelo uso de palavras com sentido figurado, chamada por Preti (1984) de gíria de grupos ligados à marginalidade. Para esse autor, a gíria é o resultado de conflitos de valores entre uma cultura dominante (representada pela sociedade mais ampla) e uma subcultura (representada por grupos sociais marginalizados).

Portanto, os adolescentes lotados em um Centro Socioeducativo utilizam a gíria como meio ideal de comunicação e identificação social, que permite distinguir seu grupo dos demais grupos sociais, visto que "o homem tende a repudiar o condicionamento massificador da linguagem que o relega linguisticamente ao anonimato da grande massa de falantes" (PRETI, 1984, p. 2).

\section{Método de geração de dados e participantes da pesquisa}

Este artigo é fruto de uma pesquisa mais ampla, ao nível de mestrado, que objetivou identificar e analisar situações de discriminação pela linguagem, enfrentadas por internos do Centro de Socioeducação de Ponta Grossa, estado do Paraná (PR). A justificativa para a escolha das quatro narrativas a serem analisadas neste trabalho baseou-se em dois motivos relevantes. Primeiramente, foram elas que mostraram mais claramente as situações de discriminação e preconceito linguístico vivenciados pelos entrevistados - o que contribuiu para que se pudesse realizar uma melhor análise das mesmas - e esses adolescentes foram os que mais apresentaram itens lexicais pertencentes ao vocabulário gírio em suas falas. 
O segundo motivo se relacionou à maior confiança que esses quatro adolescentes demonstraram para com o pesquisador e a pesquisa, visto que durante a aplicação da entrevista narrativa individualmente, alguns outros adolescentes internos manifestaram certa desconfiança em responder às perguntas realizadas pelo pesquisador e, com isso, suas narrativas se apresentaram incompletas, mais fragmentadas, controladas, - o que dificultou a obtenção de uma fala mais natural e espontânea.

Isso posto, visando identificar ocorrências vivenciadas de preconceito linguístico, para geração e coleta de dados foi utilizado o método qualitativo, com aplicação de entrevistas narrativas a quatro adolescentes, visto que, segundo Uwe Flick (2013, p. 23), a vantagem desse método é que "a análise detalhada e exata de alguns casos pode ser reproduzida, e os participantes têm muito mais liberdade para determinar o que é importante para eles e para apresentá-los em seus contextos".

Segundo Tarallo (2003), as entrevistas narrativas se constituem como instrumento de coleta de dados contextuais em que o participante é estimulado a organizar seu pensamento e relatar sobre suas experiências de maneira livre.

Para que as entrevistas atingissem os objetivos propostos para esta pesquisa, dois cuidados precisaram ser tomados no sentido de contornar a desconfiança inicial de alguns entrevistados com a presença do gravador e do pesquisador. O primeiro deles se refere à transformação do entrevistador em um aprendiz interessado, como recomenda Tarallo:

Seja qual for a natureza da situação de comunicação, seja qual for o tópico central da conversa, seja quem for o informante, o pesquisador deverá tentar neutralizar a força exercida pela presença do gravador e por sua própria presença como elemento estranho à comunidade. Tal neutralização pode ser alcançada no momento em que o pesquisador se 
decide a representar o papel de aprendiz-interessado na comunidade de falantes e em seus problemas e peculiaridades (TARALLO, 2003, p. 21).

O segundo cuidado se refere à necessidade de obter uma fala natural e espontânea dos entrevistados. Visando alcançar esse objetivo é que se optou por esse método de geração e coleta de dados, dado que

os estudos de narrativas de experiência pessoal têm demonstrado que, ao relatá-las o informante está tão envolvido emocionalmente com o que relata que presta o mínimo de atenção ao como. E é principalmente essa a situação natural de comunicação almejada pelo pesquisadorsociolinguista (TARALLO, 2003, p. 22).

Dessa forma, no presente artigo, foram analisadas quatro narrativas de adolescentes que se encontravam privados de liberdade no Centro de Socioeducação de Ponta Grossa (PR). Todos eram do sexo masculino, com grau de escolarização entre o quinto e o sétimo ano do ensino fundamental, e seus atos infracionais estavam relacionados à prática de homicídios e tráfico de drogas. Os participantes tinham entre 16 e 17 anos de idade e o tempo de cumprimento de suas medidas socioeducativas de privação de liberdade variava de um ano e dois meses até dois anos e meio.

\section{Itens lexicais coletados}

Nas narrativas dos participantes foi possível identificar alguns termos e expressões pertencentes ao vocabulário gírio, juntamente com o sentido atribuído a essas palavras: 
Tabela 1 - Itens lexicais identificados e seus significados atribuídos pelos informantes

\begin{tabular}{|c|c|}
\hline Gíria & Significado \\
\hline batida & maneira, modo \\
\hline bolado & incomodado, ressentido \\
\hline cabuloso & desagradável \\
\hline carroça & sem opinião própria \\
\hline corre & procura por algo \\
\hline daquele jeito & indignado \\
\hline de boa & tranquilo \\
\hline despenado & desempregado \\
\hline embaçada & errada \\
\hline estranhando & achando ruim \\
\hline fita mil grau & situação favorável \\
\hline issu memo & pessoa \\
\hline maluco & vez, ocasião \\
\hline mão & professora \\
\hline mestrona & saí \\
\hline me joguei & amigos, parceiros \\
\hline pá & é verdade \\
\hline sóh & sem problemas \\
\hline suave na nave & como \\
\hline tipo & de alguma forma \\
\hline tipo numas & compreendido \\
\hline to ligado & trabalho, emprego \\
\hline trampo & \\
\hline
\end{tabular}

Fonte: $\mathrm{O}$ autor

\section{Análise do corpus}

A língua portuguesa apresenta múltiplas variações, que decorrem de aspectos regionais, sociais, profissionais, entre outros. A gíria utilizada pelos adolescentes pesquisados, apesar de presente em algumas letras musicais de grupos ligados ao rap e o funk, ainda é desabonada linguística e socialmente com relação à linguagem considerada padrão. 
De acordo com Faraco (2002, p. 40), a norma padrão objetiva "neutralizar e controlar a variação linguística" e teve sua origem no século XIX, quando a elite social dominante determinou que tal norma teria como modelo a língua utilizada por escritores portugueses. Com isso, essa elite visava a afastar-se da mestiçagem e de tudo que considerava como incivilizado e "autóctone" (BAGNO, 2002, p. 180). Dentro dessa visão social e linguisticamente excludente, os relatos de discriminação linguística narrados pelos participantes desta pesquisa demonstram a perpetuação no tempo desses valores segregários, que reforçam uma identidade marcada pela exclusão social.

Dessa forma, levando em conta que a comunidade de adolescentes de um Centro Socioeducativo, por si só, representa um aspecto negativo da sociedade, a variedade linguística por eles praticada também será socialmente desprestigiada, conforme será possível constatar nas análises das narrativas a seguir:

P: Já sofreu preconceito por causa da maneira que você fala?

R: 'Sóh', com várias pessoas. Uma 'mão' eu falei desse modo e a professora me chamou a atenção na frente de todo mundo, dizendo que isso não é jeito de falar, que eu tinha que falar do jeito certo. Que não era assim que se falava. 'Me joguei' na hora e me senti 'bolado' e envergonhado (INF. 3).

A resposta indica que a professora do informante 3 não levou em conta o conhecimento deste de um modo de falar com o qual já tinha mais familiaridade e desconsiderou toda sua bagagem linguístico-cultural, por esse uso linguístico ser diferente do ensinado tradicionalmente nas escolas, o que reforça a ideia de que tudo que é diferente deve ser padronizado.

Nesse sentido, afirma Bortoni-Ricardo: 
O ensino da língua culta à grande parcela da população que tem como língua materna - do lar e da vizinhança - variedades populares da língua tem [...] consequências desastrosas: não são respeitados os antecedentes culturais e linguísticos do educando, o que contribui para desenvolver nele um sentimento de insegurança $(2005$, p. 15).

Diante dessa atitude de discriminação da professora e do consequente sentimento de vergonha do entrevistado, é possível observar a ocorrência da "insegurança linguística" no referido adolescente que, de acordo com Calvet (2002, p. 63-64), é "quando os falantes consideram seu modo de falar pouco valorizado e têm em mente outro modelo, mais prestigioso, mas que não praticam".

Tal insegurança pode ter como resultados dois comportamentos: a imitação da forma tida como prestigiosa ou o receio, medo de falar e saber que será julgado pela sua fala, visto que "existe todo um conjunto de atitudes e sentimentos dos falantes para com as línguas, para com as variedades de suas línguas e para aqueles que a utilizam" (CALVET, 2002, p. 57).

A reposta do informante 1 foi a seguinte:

P: Você se lembra de ter sofrido alguma discriminação devido ao seu jeito de falar?

R: Falei 'tô lígado', 'tipo numas' e a 'mestrona' que escutou ficou 'daquele jeito', me estranhando. Foi meio 'cabuloso'. Isso foi na escola daqui do CENSE e não foi a única 'mão' (INF. 1).

Pela análise da fala desse adolescente é possível inferir que, embora a escola que frequenta estar localizada dentro da instituição, que é o local onde essa variedade linguística é corriqueiramente utilizada, tanto pelos internos quanto pelos educadores sociais, e do entrevistado mostrar interesse em frequentá-la, o ambiente escolar, de um 
modo geral, se apresenta como um dos locais onde o preconceito linguístico está presente.

Tal ocorrência de discriminação pela linguagem se relaciona com o fato de que, no ambiente escolar, tradicionalmente, os alunos são condicionados a abandonar as práticas linguísticas que já utilizam e são forçados a aprender e praticar um modelo linguístico considerado "correto", padrão, sendo que qualquer manifestação fora desse modelo é considerada errada e, consequentemente, seu autor é reprimido, censurado e ridicularizado.

Dentro desse aspecto, afirma Bagno:

O preconceito linguístico se baseia na crença de que só existe uma única língua portuguesa digna de ser aceita, ensinada nas escolas, explicada nas gramáticas normativas e catalogadas nos dicionários e qualquer manifestação linguística que escape desse triângulo escola-gramáticadicionário é considerada, sob a ótica do preconceito linguístico, errada, feia, estropiada, rudimentar, deficiente (BAGNO, 2004, p. 38).

Essas duas ocorrências de discriminação pela linguagem no ambiente escolar demonstram que esses adolescentes foram marcados profunda e duplamente, tanto pelos professores, quanto por si mesmos, resultando em uma negação de suas identidades sociais, pois os conhecimentos culturais e linguísticos dos mesmos - que são parte de suas identidades - não foram observados.

Há também que se considerar, como dito anteriormente, que os adolescentes são vulneráveis a qualquer tipo de influência nessa etapa de vida, e como a língua representa um dos elementos constituintes de sua identidade em formação, deviam ter sido levados em consideração os seus históricos de vida e o contexto privativo de liberdade pelo qual 
passaram. A desconsideração desses aspectos demonstra e reforça o estigma que marca essas identidades marginalizadas socialmente.

Essa inadequação às regras linguísticas presentes na escola encontra respaldo nos estudos de Cella e Camargo (2009). As autoras apontam que a "maioria dos adolescentes infratores são multirepetentes, apresentando um histórico de inadaptação ao ambiente e ao cotidiano escolar" (CELLA; CAMARGO, 2009, p. 286), e indicam que as tentativas frustradas de aprendizagem podem levar à indisciplina.

Essas autoras afirmam que muitos desses adolescentes envolvidos em atos infracionais "têm uma tendência a apresentar poucos anos de estudo, com episódios de abandono escolar, [...] desestímulo quanto à aquisição de competências escolares, [...] desentendimento com colegas e professores" (CELLA; CAMARGO, 2009, p. 288).

Os apontamentos das autoras permitem confirmar o que foi observado com os informantes 1 e 3, tendo em vista que, por terem a idade de 16 e 17 anos e estarem cursando o sexto e o sétimo anos do ensino fundamental, respectivamente, todos apresentaram grande defasagem escolar. O motivo de tal defasagem pode estar relacionado tanto com os episódios de interrupção do processo de ensino-aprendizagem em virtude de terem sido privados de liberdade, quanto com a não adequação às normas linguísticas prescritas e exigidas no âmbito escolar.

Portanto, o combate ao preconceito linguístico também passa pelas práticas escolares, pois não é somente no ambiente familiar e social que tal discriminação se manifesta, fato que convida as pessoas que compõem o cenário escolar a uma reflexão em torno dessa temática.

Continuando a análise das entrevistas, tem-se a fala do informante 2: 
P: Você já sofreu algum tipo de preconceito devido ao seu modo de falar?

R: Já! Tem 'carroça' que diz que eu falo que nem bandido né, 'tipo' por eu falar 'issu memo', 'fita mil grau'... eles têm como uma coisa 'embaçada'... pra eles é feio, mas pra nós é normal. Minha mãe acha mais 'suave na nave', mas o resto não. (INF. 2)

A resposta do informante 2 apresenta um detalhe importante: a pergunta foi direcionada ao entrevistado através do pronome de tratamento 'Você', mas parte da resposta foi construída utilizando o pronome pessoal 'nós'. Esse detalhe reforça a posição de Preti (1984, p. 88), quando esse pesquisador conclui que a gíria tem, como uma das principais características, a de "representar a identidade do grupo social que a utiliza, proporcionando uma sensação de pertencimento do falante ao referido grupo".

Nessa mesma perspectiva, Le Page (1980) considera cada ato de fala como um ato de identidade, ou seja, para ele, a linguagem é o índice por excelência da identidade, visto que as regras linguísticas utilizadas pelo falante na busca de aproximação com os membros do grupo com o qual deseja se identificar são criadas no momento da enunciação, por meio de escolhas linguísticas inconscientes que se associam às múltiplas dimensões formadoras da identidade social e aos papéis que assumem na comunidade de fala.

A resposta do entrevistado permite constatar que sua fala foi relacionada com uma identidade social criminosa, ligada à bandidagem e, apesar de evidenciar essa correlação que fazem entre sua fala e a de um bandido, ele a considera normal. Embora reconheça atitudes contrárias ao uso da gíria, o adolescente demonstra certo conformismo e indiferença em relação à opinião preconceituosa sobre seu comportamento linguístico. 
Ao abordar o preconceito, a identificação e o pertencimento a grupos relativos às variedades linguísticas que fogem do considerado padrão de fala, Jespersen (1976, p. 107) defende que, "quanto mais vulgar for uma pessoa, tanto mais sua linguagem leva o selo da comunidade em que vive; quanto mais forte e original a sua personalidade, tanto mais peculiar e próprio será o colorido da sua linguagem".

A narrativa do informante 2 permite constatar a falta de conhecimento, por parte da sociedade, do conceito de variantes linguísticas, que são "diversas maneiras de se dizer a mesma coisa com o mesmo valor de verdade" (TARALLO, 2003, p. 8).

Da mesma forma, para que sejam respeitados tanto os falantes de gíria, quanto a própria gíria, é preciso que a sociedade também compreenda a relação intrínseca entre variação linguística e comunidades de falantes, já que não se aceita e "não se pode entender o desenvolvimento de uma mudança linguística sem levar em conta a vida social da comunidade em que ela ocorre" (LABOV, 2008 [1972], p. 21).

Outro entrevistado, o informante 4, também relatou os aspectos negativos que foram construídos sobre sua identidade em decorrência de sua linguagem:

P: Você já sofreu discriminação devido ao seu modo de falar?

R: Já sofri bastante. Já perdi um 'corre' por causa disso. Uma vez eu tava na região da Nova Rússia, passei numa (oficina) mecânica, e como eu tava 'despenado', pedi um 'trampo' e fiquei uns quinze minutos conversando com o dono da oficina e ele percebeu que eu falava de um modo diferente, daí olhou minha cara e falou que não ia precisar de ninguém, que já tava cheio de funcionário. Aí quando eu fui tomar água na torneira, escutei ele falando para outro 'maluco' lá que não ia aceitar vagabundo, maloqueiro. Pelo meu jeito de falar ele achou que eu fosse maloqueiro. Minha tia e minha avó também implicam bastante comigo por causa do meu jeito de falar. (INF. 4) 
É possível verificar que a linguagem utilizada pelo entrevistado "marcou" negativamente a identidade do adolescente, relacionando-o a uma identidade social tida como perigosa e impedindo-o de conseguir um emprego, pois "a atitude linguística assumida pelo falante implica a noção de identidade, que se pode definir como o conjunto de características que permitem diferenciar um grupo de outro" (AGUILERA, 2008, p. 105).

A análise da resposta possibilita observar que, além de alguns familiares do informante 4 não aceitarem o uso dessa variedade linguística, a atitude do dono da oficina com relação ao seu comportamento linguístico indica uma necessidade urgente de serem revistos certos conceitos e valores arraigados na cultura social hegemônica, não só com relação à gíria, mas também com relação à necessidade dos adolescentes que já cumpriram medidas socioeducativas de privação de liberdade de se reintegrarem à sociedade, pois este é o objetivo do processo socioeducativo, e um dos caminhos para tal reinserção social é justamente a obtenção de um emprego digno.

Essa necessidade de mudança na sociedade é defendida por Bagno:

Por mais que isso nos entristeça ou irrite, é preciso reconhecer que o preconceito linguístico está aí, firme e forte. Não podemos ter a ilusão de querer acabar com ele de uma hora para outra, porque isso só será possível quando houver uma transformação radical do tipo de sociedade em que estamos inseridos, que é uma sociedade que, para existir, precisa de discriminação de tudo o que é diferente, da exclusão da maioria em benefício de uma pequena minoria, da existência de mecanismos de controle, dominação e marginalização (BAGNO, 2004, p. 139).

Esse destaque pelo aspecto negativo da relação identidade/usos linguísticos possibilita verificar o prestígio que a linguagem pertencente à norma padrão possui com 
relação ao uso da variedade linguística praticada pelo entrevistado. Isso ocorre devido à prescrição ideológica normativa que caracteriza a língua padrão e que sujeita as demais variedades linguísticas e, consequentemente, seus usuários, a uma posição marginal e inferior, conforme aponta Monteagudo:

O prescritivismo tradicional acha-se associado à sobrevivência de estruturas sociais e esquemas de valores autoritários e discriminatórios e repousa num emaranhado de preconceitos que afinal convertem a variedade padrão num elemento chave da hegemonia e do controle em mãos de um grupo de prestígio e a tornam um pesado fardo de exclusão sociocultural (MONTEAGUDO, 2011, p. 43).

A entrevista continua com o mesmo adolescente:

P: Você acha que esse falar auxilia na comunicação de vocês?

R: 'Sóh', com os 'pá' que me entende aqui no Centro é bem 'de boa'. Eu não vou mudar minha 'batida' só pras pessoas gostarem de mim, vou continuar nessa 'batida'. (INF. 4)

A frase "Sóh, com os pá que me entende aqui no Centro é bem de boa" denota a segurança que a gíria oferece ao entrevistado. O referido trecho também evidencia como essa variedade linguística facilita o entendimento por parte de seus usuários e promove uma forte sensação de pertencimento do falante ao grupo social com o qual se identifica.

Essa relação entre gíria e grupo social é confirmada por Preti:

A gíria é caracterizada como um vocabulário especial, surge como um signo de grupo, a princípio secreto, domínio exclusivo de uma comunidade social restrita (seja a gíria dos marginais ou da polícia, dos estudantes, ou de outros grupos ou profissões). E quanto maior for o sentimento de união que liga os membros do pequeno grupo, tanto mais a linguagem gíria servirá como elemento identificador, 
diferenciando o falante na sociedade e servindo como meio ideal de comunicação, além de forma de auto-afirmação (PRETI, 1984, p. 3).

A afirmação "Eu não vou mudar minha batida só pras pessoas gostarem de mim, vou continuar nessa batida" revela que, além da importância de manter secreto esse vocabulário, o uso dessa linguagem é uma decorrência da dinâmica social e linguística, que pode ser entendida como a expressão da insatisfação desse grupo minoritário em relação ao grupo dominante e à necessidade de agressão aos costumes do grupo social maior, institucionalizado, pois, como relata Castilho (2010, p. 31), “é na língua que se manifestam os traços mais profundos do que somos, de como pensamos o mundo, de como nos dirigimos ao outro".

Esse tipo de atitude contestadora - tomada em face da urgência de rompimento com os modelos sociais tidos como corretos e adequados - e a insubmissão às regras de comportamento impostas pela cultura dominante revelam a importância que o adolescente dá à gíria. Esse pequeno trecho também denota uma possível intenção de chocar, mostrar-se intransigente, o que remete às conclusões de Labov (2008) nos estudos sobre Martha's Vineyard, em relação a um comportamento linguístico adotado pelos nativos dessa ilha para se diferenciarem dos turistas que a visitavam no verão.

Além disso, a negação do entrevistado em mudar seu modo de falar encontra respaldo em Preti (1984), quando esse autor esclarece que a gíria surge em decorrência do isolamento social de um indivíduo e seu uso indica uma reação e contestação aos valores e padrões socioculturais impostos pela ideologia da sociedade mais ampla, visto que, "falando diferente, estropiando a linguagem usual, ele agride o convencional, opõese ao uso aceito pela maioria, e deixa marcado seu conflito com a sociedade" (PRETI, 1984, p. 41). 
A análise das narrativas dos informantes aponta que a linguagem utilizada pelos entrevistados, além de ter sido relacionada a uma identidade ligada à prática de atos ilícitos, à bandidagem e vagabundagem, foi também associada a uma maneira errada e "feia" de se comunicar, representando uma forma de distinguir as pessoas boas das más, ou as adequadas das inadequadas, somente pela observação de seu comportamento linguístico. Mas é preciso considerar que tal linguagem é definida por normas socioculturais que ligam esses indivíduos a um papel social localizado à margem da sociedade, provocando uma divisão que também se reflete na língua, dado que

[...] as variedades faladas pelos grupos de maior poder político e econômico passam a ser vistas como variedades mais bonitas e até mais corretas. Mas essas variedades, que ganham prestígio porque são faladas por grupos de maior poder, nada têm de intrinsecamente superior às demais. $O$ prestígio que adquirem é mero resultado de fatores políticos e econômicos. O dialeto (ou variedade regional) falado em uma região pobre pode vir a ser considerado um dialeto "ruim", enquanto o dialeto falado em uma região rica e poderosa passa a ser visto como um "bom" dialeto (BORTONI-RICARDO, 2004, p. 34).

Portanto, o preconceito linguístico decorre da hierarquia dos grupos sociais, cujas variedades linguísticas destacam a identidade e posição social de seus falantes, consideradas superiores ou inferiores, certas ou erradas, e a diferença de posições no tabuleiro social fazem surgir atitudes e comportamentos preconceituosos em relação às variedades da língua que fogem à regra padrão.

\section{Considerações finais}


As narrativas permitiram perceber que existe uma norma linguística padronizada e normas parciais, como a que rege a linguagem de grupos minoritários, relegados à margem da sociedade, representados neste trabalho pelos adolescentes entrevistados.

As possibilidades e facilidades comunicativas presentes na gíria, embora contrariem a norma padrão, obedecem a normas específicas do grupo social ao qual pertencem seus falantes, permitindo a manifestação de suas individualidades e de seus valores.

Considerando que o objetivo do processo socioeducativo é possibilitar a reinserção social do adolescente ator de ato infracional, é relevante destacar que o sucesso ou insucesso do processo reeducativo apresenta duas faces que se complementam. De um lado, é preciso que o adolescente se esforce para internalizar valores e desenvolver comportamentos que possibilitem o convívio em sociedade. De outro, é preciso que essa mesma sociedade ofereça condições para sua reinserção social.

É dentro desse segundo aspecto que o presente trabalho pretende colaborar, pois, além das barreiras sociais que o adolescente infrator tem que superar, o uso da gíria interfere negativamente na forma com que são tratados por pessoas que acreditam existir somente uma maneira correta de se comunicar.

Assim, qualquer gênero ou manifestação de preconceito linguístico demonstra duas realidades evidentes: a falta de conhecimento detalhado e lógico da natureza heterogênea das línguas e a inflexibilidade comum à grande parte dos seres humanos, em especial daqueles que se julgam superiores e profundos conhecedores de determinados campos. Estes se encontram tão aprofundados em seus saberes e valores, que por ignorarem a necessária evolução do conhecimento na área de estudos linguísticos, terminam por reforçar a exclusão social daqueles a que julgam diferentes e inferiores. 


\section{Referências}

AGUILERA, Vanderci de Andrade. Crenças e atitudes linguísticas: o que dizem os falantes das capitais brasileiras. In: Anais GEL, 2008. Disponível em:

<http://www.gel.org.br/estudoslinguisticos/volumes/37/EL_V37N2_11.pdf>. Acesso em: 13 mar. 2018.

BAGNO, Marcos. Linguística da norma. São Paulo: Edições Loyola, 2002.

Preconceito linguístico: o que é, como se faz. 29. ed. São Paulo: Edições Loyola, 2004.

BRASIL. Ministério da Justiça. Conselho Nacional de Justiça. Cadastro Nacional de Adolescentes em Conflito com a Lei. Brasília, 2016.

Ministério dos Direitos Humanos (MDH). Levantamento Anual SINASE 2016.

Brasília: 2018.

BORTONI-RICARDO, Stella Maris. Educação em língua materna: a sociolinguística na sala de aula. São Paulo: Parábola Editorial, 2004.

Nós cheguemu na escola, e agora? São Paulo: Parábola Editorial, 2005.

CALVET, Louis - Jean. Sociolinguística: uma introdução crítica. Tradução Marcos Marcionilo. São Paulo: Parábola Editorial, 2002.

CASTILHO, Ataliba Teixeira de. Nova gramática do português brasileiro. São Paulo: Contexto, 2010.

CELLA, Silvana Machado; CAMARGO, Dulce Maria Pompêo. Trabalho pedagógico em adolescentes em conflito com a lei: feições da exclusão/inclusão. Educação e Sociedade, Campinas, SP, v. 30, n. 106, p. 281-299, jan./abr. 2009.

ERIKSON, Erik H. Identity: youth and crisis. 12. ed. New York: Norton \& Company, 1994.

FARACO, Carlos Alberto. Norma-padrão brasileira: desembaraçando alguns nós. In:

BAGNO, Marcos. (org.). Linguística da norma. São Paulo: Edições Loyola, 2002, p. 37-61.

FLICK, Uwe. Introdução à metodologia de pesquisa: um guia para iniciantes. Tradução Magda Lopes. Porto Alegre: Penso, 2013.

JESPERSEN, Otto. Nature, évolution et origenes. Paris: Payot, 1976. 
LABOV, William. Padrões sociolinguísticos. São Paulo: Parábola Editorial, 2008.

LE PAGE, Robert. Projection, focusing and diffusion. In: York Papers in Linguistics. v. 9. University of York, 1980.

MONTEAGUDO, Henrique. "Variação e norma linguística: Subsídios para uma (re)visão". In: BAGNO, M.; LAGARES, X. C. (orgs.). Políticas da norma e conflitos linguísticos. São Paulo: Parábola Editorial, 2011, p. 35-47.

PRETI, Dino. Sociolinguística: os níveis de fala, um estudo sociolinguístico do diálogo na Literatura Brasileira. 3. ed. São Paulo: Nacional, 1977.

A gíria e outros temas. São Paulo: Edusp, 1984.

SALLES, Leila Maria Ferreira. Infância e adolescência na sociedade contemporânea: alguns apontamentos. Estudos de Psicologia, Campinas, SP, v. 22, n. 1, p. 33-41, 2005.

SCHERRE, Marta Maria Pereira. Doa-se lindos filhotes de poodle. Variação linguística, mídia e preconceito. 2. ed. São Paulo: Parábola Editorial, 2008.

TARALLO, Fernando. A pesquisa sociolinguística. São Paulo: Ática, 2003.

VICENTIN, Maria Cristina Gonçalves. A vida em rebelião: jovens em conflito com a lei. São Paulo: Hucitec, 2005.

Recebido em 18 de agosto de 2018. Aceite em 30 de novembro de 2018. 